\title{
Editorial
}

\section{The ramification of COVID-19 on the other diseases- Time for a prompt action}

\author{
Sankalp Yadav ${ }^{1} *$, Gautam Rawal ${ }^{2}$ \\ ${ }^{1}$ Dept. of Medicine \& Tuberculosis, Shri Madan Lal Khurana Chest Clinic, Moti Nagar, NDMC, New Delhi, India \\ ${ }^{2}$ Dept. of Respiratory Intensive Care, Max Super Specialty Hospital, Saket, New Delhi, India
}

\section{A R T I C L E I N F O}

Article history:

Received 01-07-2020

Accepted 01-09-2020

Available online 16-09-2020
(C) 2020 Published by Innovative Publication. This is an open access article under the CC BY-NC license (https://creativecommons.org/licenses/by-nc/4.0/)
The world is plagued by the historic pandemic of COVID-19. ${ }^{1,2}$ The impact of this pandemic has been evident in every section of society. ${ }^{1}$ In a major part of the world, the pandemic has resulted in large scale morbidity and mortality. ${ }^{1}$ The effect is not only limited to healthcare but to the overall felicity i.e., mental, physical, psychological, and the financial wellbeing of the society. ${ }^{1}$ This pandemic has devastated the healthcare systems of the developed world and also has severely affected the already weak and fragile healthcare systems of the developing countries. ${ }^{3}$ The low-income countries with meagre expenditure on the health budget are at the receiving end. ${ }^{3}$ The improper planning, lack of commitment, corruption, lack of vision for the future has led to chaos and pandemonium in the pandemic of COVID-19. ${ }^{2}$ These low-income countries were already having a high burden of morbidity and mortality due to other communicable and non-communicable diseases and now with the uncontrolled and geometric progression of the COVID-19 cases, the treatment/care of these diseases has suffered remarkably. ${ }^{4}$ The recent survey by WHO conducted in the 155 countries revealed that the impact of the pandemic on these diseases was global with a greater degree of severity in the low-income countries. ${ }^{4}$ There are confusion and fear of death among the general public. ${ }^{1}$ The already overburdened health care systems are stretched

\footnotetext{
* Corresponding author.

E-mail address: drsankalpyadav@gmail.com (S. Yadav).
}

to their limits, the staff working in these units are having multiple issues due to mental and physical exhaustion. ${ }^{1}$ The ramification of the COVID-19 on the other diseases will be deadly and lack of or improper attention to these already existing diseases would result in a precarious situation.

The diseases like cancer, HIV, tuberculosis (TB), diabetes, hypertension, renal diseases, etc. are considered as important since people with any of these comorbidities have a higher chance of being affected by the COVID19. ${ }^{4}$ The WHO survey mentioned that healthcare services have been partially or completely unsettled in several countries. ${ }^{4}$ The disruption of healthcare services is to the extent of $53 \%$ for hypertension treatment in the surveyed countries; $49 \%$ for management of diabetes and diabetesrelated complications; $42 \%$ for cancer treatment, and $31 \%$ for cardiovascular emergencies. ${ }^{4}$ Besides, the rehabilitation services have taken a back step in almost two-thirds $(63 \%)$ of the surveyed countries. ${ }^{4}$

Many screening programs like breast and cervical cancer have been postponed. ${ }^{4}$ The programs like active case finding for TB have also been postponed. ${ }^{5}$ Dental services, ophthalmology services, ENT services, and tobacco cessation activities have been deferred. There is a drastic reduction in the TB case notifications. ${ }^{6}$ The impact on such communicable diseases known to mankind since long will directly affect the efforts and timelines set to achieve goals like that of TB elimination. ${ }^{7}$ In the recent past as a part of the Sustainable Development Goals, substantial 
progress has been made in reducing the burden of HIV, TB, and malaria, and ambitious targets have been set for reaching very low levels of the disease burden by $2030 .^{7}$ However, the halts in the control programs due to COVID19 could result in major setbacks. ${ }^{7}$ The fragile gains that have been achieved for the elimination of TB under END TB strategy by the WHO and by countries like India which aims to eliminate TB by 2025 could be adversely affected by the COVID- 19 .

Hogan et al. 2020, reported that the lack of attention towards other diseases will lead to great despoliation. ${ }^{7}$ In a study, they reported that in high-burden settings, mortality due to HIV, TB, and malaria over five years could increase by up to $10 \%, 20 \%$, and $36 \%$, respectively, compared with if there was no COVID-19 pandemic. $^{7}$ This could largely be due to a major portion of the patients suffering from such diseases rely on the large scale national and international programs inclined at the control or elimination of such diseases. $^{7}$ The pandemic of COVID-19 has adversely affected these national and international disease control programs and thus there could be a large population that could be devoid of the care which they would have got in the absence of the pandemic. ${ }^{7}$ The impact of the pandemic is also largely seen on the vaccination programs for vaccinepreventable diseases that were postponed or are not attended by people due to fear of COVID-19, thus posing a serious threat to mankind with the development of resistant strains of the microbes. ${ }^{8}$ As per the estimates by the GAVI Alliance (formerly the Global Alliance for Vaccines and Immunisation) at least 13.5 million people in thirteen of the world's least developed nations will not be vaccinated against measles, polio, and human papillomavirus (HPV) in the short term, and in the long-term, millions more will follow. ${ }^{8,9}$ This will result in large scale morbidity and mortality which could have been averted. ${ }^{9}$

The governments are drafting new policies and a number of changes or modifications to the existing guidelines for the management of the other diseases in the current pandemic situation are evident, yet with a majority of the population with these diseases, residing in low- and middle-income countries, a collective effort both at local and international level is essential and imperative. The provisions like telemedicine and triaging are the need of the hour as these would help in reducing the patient load on the already overwhelmed healthcare systems and this will also help in maintaining the social distancing norms. With the definite cure of COVID-19 not available, it's important that the meticulous planning and judicious use of available resources inclined at minimizing the COVID-19 impact be done.

\section{Acknowledgments}

None.

\section{Source of Funding}

None.

\section{Conflicts of Interest}

None.

\section{References}

1. Yadav S, Rawal G. The mental health status of the general public and healthcare professionals in the COVID-19 pandemic. IP Indian J Immunol Respir Med. 2020;5(2):72-4.

2. Yadav S, Rawal G. Corona virus pandemic- A threat to humanity. IP Indian J Immunol Respir Med. 2020;5(1):1-3.

3. UNICEF. As COVID-19 devastates already fragile health systems, over 6,000 additional children under five could die a day, without urgent action. Available from URL- https://www.unicef. org /press-releases/covid-19-devastates-already-fragile-health-systemsover-6000-additional-children. Last accessed 2020 on September 1.

4. WHO. COVID-19 significantly impacts health services for noncommunicable diseases. Available from URL- https://www.w ho.int/news-room/detail/01-06-2020-covid-19-significantly-impacts-h ealth-services-for-noncommunicable-diseases. Last accessed 2020 on September 1.

5. Yadav S, Rawal G. Active case finding- A new tool in the fight against TB. IP Indian J Immunol Respir Med. 2018;3(1):1-2.

6. Vijayan S, Pai M. TB during COVID-19. Available from URL- https:// www.thehindu.com/sci-tech/science/tb-during-covid-19/article319346 32.ece. Last accessed 2020 on September 1;.

7. Hogan AB, Jewell BL, Sherrard-Smith E, Vesga JF, Watson OJ, Whittaker C, et al. Potential impact of the COVID-19 pandemic on HIV, tuberculosis, and malaria in low-income and middle-income countries: a modelling study. Lancet Glob Health. 2020;8:e1132-41.

8. Impact of COVID-19 on vaccine-preventable diseases and antibiotic resistance. Available from URL- https://www.reactgroup.org/news-and -views/news-and-opinions/year-2020/impact-of-covid-19-on-vaccinepreventable-diseases-and-antibiotic-resistance/. Last accessed 2020 on September 1 .

9. GAVI. World Immunization Week 2020. Available from URL- https:// www.gavi.org/world-immunization-week-2020. Last accessed 2020 on September 1.

Cite this article: Yadav S, Rawal G. The ramification of COVID-19 on the other diseases- Time for a prompt action. IP Indian J Immunol Respir Med 2020;5(3):135-136. 